\title{
PENGARUH PEMBERIAN EKSTRAK UMBI BIT (Beta vulgaris L.) TERHADAP PENURUNAN KADAR LDL TIKUS PUTIH JANTAN (Rattus norvegicus) YANG DIINDUKSI SUKROSA \\ ${ }^{1)}$ Monika Septiana Manurung dan ${ }^{2)}$ Sonlimar Mangunsong \\ ${ }^{1,2)}$ Politeknik Kesehatan Kemenkes Palembang Prodi Farmasi
}

Email: monikaseptiana2697@gmail.com

\begin{abstract}
ABSTRAK
Latar Belakang : Tingginya kadar kolesterol dalam darah dapat berpengaruh terhadap kesehatan jantung dan pembuluh darah. Menurut penelitian, umbi bit mengandung zat aktif seperti betalain, flavonoid, tanin dan saponin. Zat-zat tersebut diduga mampu menurunkan kadar LDL kolesterol dalam darah. Penelitian ini ditujukan untuk meneliti apakah umbi bit (Beta vulgaris L.) mampu menurunkan kadar LDL darah tikus putih jantan. Metode : Metode yang digunakan adalah penelitian eksperimental yang dilakukan pada hewan percobaan tikus putih jantan (Rattus novergicus) sebanyak2 4 ekor yang dibagi menjadi 6 kelompok yaitu: kelompok kontrol normal; kelompok induksi sukrosa); kelompok induksi suspensi simvastatin 0,18 mg/200 grBB); kelompok induksi ekstrak dosis $20 \mathrm{mg} / 200 \mathrm{grBB}$; kelompok induksi ekstrak dosis $40 \mathrm{mg} / 200$ grBB; kelompok induksi ekstrak dosis 80 $\mathrm{mg} / 200$ grBB. Induksi sukrosa bertujuan untuk meningkatkan kadar LDL dalam darah tikus putih jantan yang dilakukan secara oral. Pengukuran kadar LDL dalam darah tikus putih jantan yang dilakukan dengan mengambil darah tikus menggunakan alat biosystem A-15.
\end{abstract}

Hasil : Hasil uji ANOVA one-way menunjukkan adanya perbedaan yang bermakna antara kelompok II (kelompok negatif) dengan kelompok I (kontrol normal), kelompok III (kontrol positif), kelompok IV (ekstrak dosis I), kelompok V (ekstrak dosis II), dan kelompok VI (ekstrak dosis III) dengan signifikan $p=0,000(p<0,05)$. Kesimpulan : Ekstrak umbi bit (Beta vulgaris L.) mampu menurunkan kadar LDL dalam darah tikus putih jantan selama 21 hari .

\section{Kata Kunci: Buah Bit, LDL; Sukrosa, Kolesterol}

\section{PENDAHULUAN}

Kolesterol yang tidak seimbang dalam tubuh manusia telah menjadi masalah kesehatan di negara-negara maju dan juga negara-negara

berkembang. Kecenderungan perubahan pola makan masyarakat yang didominasi oleh makanan berlemak tinggi dan rendah serat (junkfood), gaya hidup merokok serta kurang gerak merupakan penyebab timbulnya berbagai penyakit yang berhubungan dengan kolesterol. (Ariantari, Yowani dan Swastini, 2010.). Tingginya kadar kolestrol dalam darah seseorang dapat bepengaruh terhadap kesehatan jantung. Hasil Riskesdas (Riset Kesehatan Dasar) 2013 menunjukan Penyakit Jantung Koroner (PJK) berada pada posisi ketujuh tertinggi PTM (Penyakit Tidak Menular) di Indonesia. WHO memperkirakan

kematian akibat PJK di Indonesia mencapai $17,5 \%$ dari total kematian. Prevalensi penderita PJK berdasarkan diagnosis dokter di Sumatera Selatan sebesar $0,4 \%$ atau tercatat sebanyak 21.919 orang pada tahun 2013 (Kementerian Kesehatan,

2014). Umbi Bit (Beta vulgaris L.) merupakan salah satu tanaman yang 
digunakan sebagai obat. Umbi Bit (Beta vulgaris L.) dikenal memiliki berbagai khasiat diantaranya untuk diuretik, pencahar dan aktivitas anti inflamasi, ekspektoran dan sifat karminatif (Babu dan Gowri, 2010). Umbi Bit (Beta vulgaris L.) memiliki senyawa betalain, flavonoid, saponin dan tanin yang mencegah oksidasi LDL dan bekerja sebagai inhibitor enzim HMG-KoA reduktase sehingga sintesis kolesterol menurun (Boutenko, 2015; Widawati dan Heni, 2013; Tesoriere et al, 2004). Berdasarkan hal tersebut sehingga dilakukan penelitian "Pengaruh Pemberian Ekstrak Umbi Bit (Beta vulgaris L.) Terhadap Penurunan Kadar LDL Tikus Putih Jantan (Rattus norvegicus) yang Diinduksi Sukrosa".

\section{METODE PENELITIAN}

Jenis penelitian ini adalah penelitian eksperimental dengan desain penelitian "Pre Test and Post Test Control Group Design" menggunakan tikus putih jantan

\section{Bahan dan Hewan Uji}

Bahan : Umbi Bit (Beta vulgaris L.) yang diperoleh di pasar 16 Ilir Palembang dengan massa total $8 \mathrm{~kg}$. Hewan Uji : Hewan yang digunakan tikus putih jantan (Rattus norvegicus) dengan berat rata-rata 150-200 gr. Persiapan Simplisia : Umbi Bit (Beta vulgaris L.) dicuci bersih dengan air mengalir, dirajang, lalu dikering anginkan. Kemudian timbang sebanyak 500 gram, masukkan ke dalam botol coklat (maserasi) dengan tutup yang dapat melindungi simplisia tersebut. Pembuatan Ekstrak : Umbi bit ditimbang sebanyak 500 gram di maserasi dalam pelarut etanol $80 \%$ lalu cek $\mathrm{pH}$ ( $\mathrm{pH} 3-7$ ) bila terlalu basa tambahkan asam asetat. Dan di destilasi vakum menggunakan rotary evaporator untuk mendapatkan ekstrak kental.

\section{Pengujian Efek Ekstrak Umbi Bit (Beta vulgaris L.). Pengujian efek ekstrak umbi} bit dilakukan dengan metode Pre Test and Post Test Control Group Design dengan dosis uji Ekstrak Umbi Bit (Beta vulgaris L.) $100 \mathrm{mg} / \mathrm{KgBB}, 200 \mathrm{mg} / \mathrm{KgBB}$ dan 400 $\mathrm{mg} / \mathrm{KgBB}$. Pembanding yang digunakan tablet simvastatin $10 \mathrm{mg}$.

Prosedur yang dilakukan:

1. Hewan uji dipuasakan terlebih dahulu selama kurang lebih 12 jam sebelum percobaan, tetapi air minum tetap diberikan.

2. Hewan uji dibagi menjadi 6 kelompok yang masing-masing terdiri atas 4 ekor.

3. Induksi kuning telur puyuh 1,4 gr dan larutan sukrosa 1,6 gr selama 7 hari maka dilakukan pre test, satu hewan uji tiap kelompok ditentukan kadar kolesterol LDL

4. Hewan diberi sediaan uji sesuai kelompoknya secara oral selama 14 hari.

5. Pengambilan sampel darah dilakukan pada hari ke-21 melalui intrakardial.

6. Sampel darah diperiksa kadar LDL di Balai Besar Laboratorium Kesehatan Palembang.

\section{HASIL DAN PEMBAHASAN HASIL}

Pada penelitian ini bahan yang digunakan adalah Umbi Bit (Beta vulgaris L.) yang diperoleh dari pasar 16 ilir Palembang. Telah diketahui bahwa umbi bit mengandung betalain, flavonoid, saponin dan tanin.

Hewan uji di aklimasi selama 7 hari dan dilakukan test pada kelompok normal dan didapatkan hasil pada tabel 1 . 
Tabel 1. Kadar LDL Dalam Darah Tikus Putih Jantan Hari ke- 7 dan 21

\begin{tabular}{|c|c|c|c|c|c|c|}
\hline \multirow[b]{2}{*}{ Kelompok } & \multirow[b]{2}{*}{ Perlakuan } & \multirow{2}{*}{$\begin{array}{c}\text { BB } \\
\text { (gram) }\end{array}$} & \multicolumn{4}{|c|}{ Kadar LDL (mg/dl) } \\
\hline & & & Hari ke-7 & Mean \pm SD & $\begin{array}{c}\text { Hari ke- } \\
21 \\
\end{array}$ & Mean \pm SD \\
\hline \multirow{4}{*}{ I } & Kontrol & 170 & \multirow{4}{*}{25,15} & & 6,51 & \multirow{4}{*}{$6,99 \pm 0,97$} \\
\hline & Normal Tanpa & 160 & & $25,15 \pm$ & 8,28 & \\
\hline & Perlakuan & 180 & & 10,72 & 7,12 & \\
\hline & генакиап & 170 & & & 6,05 & \\
\hline \multirow{4}{*}{ II } & Kontrol & 180 & \multirow{4}{*}{25,15} & & 29,36 & \multirow{4}{*}{$29,41 \pm 0,73$} \\
\hline & Negatif Diberi & 190 & & $25,15 \pm$ & 28,72 & \\
\hline & Larutan & 170 & & 10,72 & 30,42 & \\
\hline & Sukrosa & 180 & & & 29,13 & \\
\hline \multirow{4}{*}{ III } & Kontrol Positif & 160 & \multirow{4}{*}{25,15} & \multirow{4}{*}{$\begin{array}{c}25,15 \pm \\
10,72\end{array}$} & 8,51 & \multirow{4}{*}{$7,42 \pm 0,96$} \\
\hline & Diberi Larutan & 150 & & & 6,19 & \\
\hline & $\begin{array}{l}\text { Sukrosa + } \\
\text { Suspensi }\end{array}$ & 170 & & & 7,64 & \\
\hline & Simvastatin & 160 & & & 7,35 & \\
\hline \multirow{4}{*}{ IV } & Diberi Larutan & 150 & \multirow{4}{*}{25,15} & \multirow{4}{*}{$\begin{array}{c}25,15 \pm \\
10,72\end{array}$} & 7,96 & \multirow{4}{*}{$9,04 \pm 1,39$} \\
\hline & $\begin{array}{l}\text { Sukrosa + } \\
\text { Ekstrak Umbi }\end{array}$ & 170 & & & 10,05 & \\
\hline & Bit 0,20 & 160 & & & 7,73 & \\
\hline & $\mathrm{mg} / \mathrm{grBB}$ & 160 & & & 10,44 & \\
\hline \multirow{4}{*}{$\mathrm{V}$} & Diberi Larutan & 170 & \multirow{4}{*}{25,15} & \multirow{4}{*}{$\begin{array}{c}25,15 \pm \\
10,72\end{array}$} & 8,51 & \multirow{4}{*}{$8,02 \pm 0,49$} \\
\hline & Sukrosa + & 190 & & & 8,12 & \\
\hline & Ekstrak Umbi & 180 & & & 7,35 & \\
\hline & $\begin{array}{c}\mathrm{Bit} 0,40 \\
\mathrm{mg} / 200 \mathrm{grBB}\end{array}$ & 180 & & & 8,12 & \\
\hline \multirow[t]{4}{*}{ VI } & Diberi Larutan & 180 & \multirow{4}{*}{25,15} & \multirow{4}{*}{$\begin{array}{c}25,15 \pm \\
10,72\end{array}$} & 5,80 & \multirow[t]{4}{*}{$7,22 \pm 1,11$} \\
\hline & Sukrosa + & 190 & & & 7,35 & \\
\hline & Ekstrak Umbi & 170 & & & 7,25 & \\
\hline & $\begin{array}{c}\text { Bit } 0,80 \\
\mathrm{mg} / 200 \mathrm{grBB}\end{array}$ & 190 & & & 8,51 & \\
\hline
\end{tabular}


Tablet 2. Data LDL Hasil Analisis Statistik ANOVA one-way dengan uji Tukey

\begin{tabular}{|c|c|c|c|c|c|}
\hline Kelompok & & $\mathrm{N}$ & Mean \pm SD & Sig & $\begin{array}{l}\text { Penilaian } \\
\text { Perbedaan }\end{array}$ \\
\hline I & $\begin{array}{l}\text { II } \\
\text { III } \\
\text { IV } \\
\text { V } \\
\text { VI }\end{array}$ & $\begin{array}{l}4 \\
4 \\
4 \\
4 \\
4\end{array}$ & $\begin{array}{c}29,4050 \pm 0,73 \\
7,4225 \pm 0,96 \\
9,0450 \pm 1,39 \\
8,0250 \pm 0,49 \\
7,2275 \pm 1,11\end{array}$ & $\begin{array}{l}0.000 \\
0.988 \\
0.077 \\
0.675 \\
0.999\end{array}$ & $\begin{array}{l}\text { Bermakna } \\
\text { Tidak Bermakna } \\
\text { Tidak Bermakna } \\
\text { Tidak Bermakna } \\
\text { Tidak Bermakna }\end{array}$ \\
\hline II & $\begin{array}{l}\text { I } \\
\text { III } \\
\text { IV } \\
\text { V } \\
\text { VI }\end{array}$ & $\begin{array}{l}4 \\
4 \\
4 \\
4 \\
4\end{array}$ & $\begin{array}{l}6,9900 \pm 0,97 \\
7,4225 \pm 0,96 \\
9,0450 \pm 1,39 \\
8,0250 \pm 0,49 \\
7,2275 \pm 1,11\end{array}$ & $\begin{array}{l}0.000 \\
0.000 \\
0.000 \\
0.000 \\
0.000\end{array}$ & $\begin{array}{l}\text { Bermakna } \\
\text { Bermakna } \\
\text { Bermakna } \\
\text { Bermakna } \\
\text { Bermakna }\end{array}$ \\
\hline III & $\begin{array}{c}\text { I } \\
\text { II } \\
\text { IV } \\
\text { V } \\
\text { VI }\end{array}$ & $\begin{array}{l}4 \\
4 \\
4 \\
4 \\
4\end{array}$ & $\begin{array}{c}6,9900 \pm 0,97 \\
29,4050 \pm 0,73 \\
9,0450 \pm 1,39 \\
8,0250 \pm 0,49 \\
7,2275 \pm 1,11\end{array}$ & $\begin{array}{l}0.988 \\
0.000 \\
0.231 \\
0.950 \\
1.000\end{array}$ & $\begin{array}{l}\text { Tidak Bermakna } \\
\text { Bermakna } \\
\text { Tidak Bermakna } \\
\text { Tidak Bermakna } \\
\text { Tidak Bermakna }\end{array}$ \\
\hline IV & $\begin{array}{c}\text { I } \\
\text { II } \\
\text { IV } \\
\text { V } \\
\text { VI }\end{array}$ & $\begin{array}{l}4 \\
4 \\
4 \\
4 \\
4\end{array}$ & $\begin{array}{c}6,9900 \pm 0,97 \\
29,4050 \pm 0,73 \\
7,2275 \pm 1,11 \\
8,0250 \pm 0,49 \\
7,2275 \pm 1,11\end{array}$ & $\begin{array}{l}0.077 \\
0.000 \\
0.231 \\
0.688 \\
0.144\end{array}$ & $\begin{array}{l}\text { Tidak Bermakna } \\
\text { Bermakna } \\
\text { Tidak Bermakna } \\
\text { Tidak Bermakna } \\
\text { Tidak Bermakna }\end{array}$ \\
\hline $\mathrm{V}$ & $\begin{array}{l}\text { I } \\
\text { II } \\
\text { III } \\
\text { IV } \\
\text { V }\end{array}$ & $\begin{array}{l}4 \\
4 \\
4 \\
4 \\
4\end{array}$ & $\begin{array}{c}6,9900 \pm 0,97 \\
29,4050 \pm 0,73 \\
7,2275 \pm 1,11 \\
9,0450 \pm 1,39 \\
7,2275 \pm 1,11\end{array}$ & $\begin{array}{l}0.675 \\
0.000 \\
0.950 \\
0.688 \\
0.855\end{array}$ & $\begin{array}{l}\text { Tidak Bermakna } \\
\text { Bermakna } \\
\text { Tidak Bermakna } \\
\text { Tidak Bermakna } \\
\text { Tidak Bermakna }\end{array}$ \\
\hline VI & $\begin{array}{l}\text { I } \\
\text { II } \\
\text { III } \\
\text { IV } \\
\text { V }\end{array}$ & $\begin{array}{l}4 \\
4 \\
4 \\
4 \\
4 \\
4\end{array}$ & $\begin{array}{c}6,9900 \pm 0,97 \\
29,4050 \pm 0,73 \\
7,2275 \pm 1,11 \\
9,0450 \pm 1,39 \\
8,0250 \pm 0,49\end{array}$ & $\begin{array}{l}0.999 \\
0.000 \\
1.000 \\
0.144 \\
0.855\end{array}$ & $\begin{array}{l}\text { Tidak Bermakna } \\
\text { Bermakna } \\
\text { Tidak Bermakna } \\
\text { Tidak Bermakna } \\
\text { Tidak Bermakna }\end{array}$ \\
\hline
\end{tabular}

\section{PEMBAHASAN}

Setelah dilakukan induksi terhadap 5 kelompok dengan kuning telur selama 7 hari. dan paada hari ke ke-8 dilakukan pretest pada hewan uji tiap kelompok tetapi hasil yang diperoleh tidak menunjukan peningkatan kadar LDL sehingga induksi diganti dengan sukrosa 1,6 gr selama 7 hari dan dilakukan pre-test. Hasil yang didapatkan menunjukan kadar LDL tikus putih jantan meningkat dengan rata-rata 25,151. Kelompok III, IV, V dan VI diberi perlakuan sesuai dosis selama 14 hari. Hasil uji umbi bit terhadap penurunan kadar LDL dapat dilihat pada tabel 1.

Pada kelompok uji untuk kelompok IV dengan dosis $20 \mathrm{mg} / 200 \mathrm{grBB}$, kelompok $\mathrm{V}$ dengan dosis 40 $\mathrm{mg} / 200 \mathrm{grBB}$, dan kelompok VI dengan dosis $80 \mathrm{mg} / 200$ grBB tidak terdapat perbedaan penurunan yang signifikan dengan kelompok III (kontrol positif) dengan angka $0.231,0.950$ dan 1.000 ( $>0,05)$ lihat pada tabel 2. Hal ini menunjukkan tidak adanya perbedaan penurunan kadar LDL darah tikus antara 
kelompok IV, V, VI dengan kelompok III.

Simvastatin sebagai kontrol positif memiliki pengaruh terhadap penurunan kadar LDL. Diketahui bahwa simvastatin bekerja dengan cara menghambat HMGCoA reduktase secara kompetitif pada proses sintesis kolesterol dihati. Simvastatin akan menghambat HMG-CoA reduktase mengubah asetil-CoA menjadi asam mevalonat akhirnya terbentuk kolesterol sehingga mengakibatkan berkurangnya kadar kolesterol (Tjay \& Rahardja, 2007).

Dari ketiga kelompok yang diberi ekstrak umbi bit, menunjukkan penurunan kadar LDL yang sama seperti simvastatin

\section{KESIMPULAN}

Ekstrak Umbi Bit (Beta vulgaris L.) dengan dosis yang semakin tinggi memberikan efek yang sama terhadap penurunan kadar LDL dalam darah hewan percobaan tikus putih jantan (Rattus norvegicus). Dan memiliki efek yang setara dengan tablet simvastatin.

\section{DAFTAR PUSTAKA}

Ariantari., N.P. Yowani., S.C.

Swastini., D.A. 2010. Uji Aktivitas Penurunan Kolesterol Produk Madu Herbal Yang Beredar Di Pasaran Pada Tikus Putih Diet Lemak Tinggi. Jurnal Kimia 4. Januari 2010 : 15-19.

Babu, V.L.A dan R. Gowri. 2010.

Evaluation of Antioxidant Activity of Beta vulgaris Root Extract in Rats. Asian Journal of Chemistry. Vol 22
No 5: 3385-3389. Boutenko, V. 2015. Green for Life. B First, Yogyakarta, Indonesia, Hal. 30-31.

Kementerian Kesehatan RI. 2014. Info Datin Pusat Data dan Informasi Kementerian Kesehatan RI Situasi Kesehatan Jantung. Kementerian Kesehatan RI Pusat Data dan Informasi. Jakarta Selatan.

Tjay, Tan Hoan., Rahardja, dan Kirana. 2007. Obat-Obat Penting: Khasiat, penggunaan, dan efek-efek sampingnya. Ed.VI. Jakarta : Gramedia. Hal. 569, 587

Tesoriere L, Allegra M, Butera D, dan Livrea M. 2004. Absorption,

Excretion, And Distribution Of Dietary Antioxidant Betalain In

LDLs: Potential Health Effects Of Betalains In Human. Am J Clin Nutr 80, 941-945, 2004.

Widawati. M dan Heni. P. 2013.

Efektivitas Ekstrak Buah Beta vulgaris L(Buah Bit) Dengan Berbagai Fraksi Pelarut Terhadap Mortalitas Larva Aedes aegeypti. Jurnal Aspirator Vol.5 No.1, 2013: 23-29. 